\title{
From improved survival to potential cure in patients with metastatic breast cancer
}

\author{
Tadashi Kobayashi
}

Published online: 11 February 2012

(C) The Japanese Breast Cancer Society 2012

Metastatic breast cancer (MBC) is hard to cure by the therapies currently available and median long-term survival in MBC has been reported as either 18-24 months [1] or 2-4 years [2]. Even the definition of "cure" for MBC remains controversial. Some suggest that cure means that every single cancer cell should be eradicated, permitting a normal life span without threat of recurrence [3, 4]. Others, however, propose that cure does not necessarily mean destroying every cancer cell, but rather rendering the disease harmless (without clinically significant adverse effects) for prolonged periods [5]. As medians for survival periods in $\mathrm{MBC}$ patients are generally short, reports on prognosis of MBC longer than 3-5 years are extremely limited. The first evidence for poor long-term prognosis in MBC was reported by Greenberg et al. [6] and Rahman et al. [7] based on an observational study conducted from 1973 to 1982 . This study assessed the outcome of 1,581 relapsing breast cancer cases treated with a combination regimen using anthracycline and alkylating agents as a first-line approach. Complete response (CR) rate was $16.6 \%$ and only $3.1 \%$ of the entire study population or $18.6 \%$ of those who achieved CR remained disease-free for more than 5 years. During the entire observation period (median approximately 16 years), only $1.6 \%$ of the total patents analyzed retained their CR status. Interestingly, in a nonselective population-based study cohort regarding longterm MBC survivals and their characteristics, 5 out of 149 (3.4\%) MBC patients remained without evidence of

T. Kobayashi $(\bowtie)$

Department of Clinical Oncology and Hematology,

The Jikei University School of Medicine,

3-25-8 Nishi-shimbashi, Minato-ku,

Tokyo 105-8461, Japan

e-mail: tadkob-1@kk.iij4u.or.jp; kobayashi@jikei.ac.jp relapsing disease for 9-14 years, 4 out of whom never received chemotherapy. This observation implied that aggressive use of strong chemotherapy regimes may not necessarily be a key factor for survival [4].

As we discussed above, though based on the limited reports, long-term prognosis for $\mathrm{MBC}$ is devastating. Have we, then, made any progress in treating MBC? Transition in the estimated survival of the MBC patients over the last century is summarized in Table 1. Between 1920 and 1980, combination drug programs have become available, yet may not have resulted in dramatic improvement in overall survival (OS) of the MBC patients [8]. OS observed between 1942 and 1975 also showed no significant prolongation of survival time in patients with MBC [9]. We had to wait till the twenty-first century for some hope of a cure to be reported, at least in a portion of the MBC patients [1012]. In particular, since the introduction of doxorubicin to our clinical practice in mid-1970s, prognosis of $\mathrm{MBC}$ continued to improve, though more recent studies involving newer systemic therapy regimens are often focused on highly selected patient populations and therefore the effects of various biases are not negligible in such studies. Newer and more effective systemic agents for the treatment of MBC along with advances in supportive care, and the development of diagnostic technologies for the earlier detection of $\mathrm{MBC}$ are also accelerating our progress.

Such anticipation for improved outcome in MBC was further supported by the systematic review of 370 randomized trials $(54,189$ subjects in total) conducted between 1973 and 2007 with chemotherapy and/or targeted therapy [13]. The meta-analysis suggested that stepwise improvements of therapeutic efficacies either by chemotherapy or targeted treatments have cumulatively led, despite each observation period being relatively short, to major improvement in the tentative survival of patients with 
Table 1 Transition of the estimated overall survival of metastatic breast cancer since the early twentieth century

\begin{tabular}{|c|c|c|c|c|c|c|}
\hline \multirow[t]{2}{*}{ References } & \multirow[t]{2}{*}{ Study period } & \multirow[t]{2}{*}{ Treatment } & \multirow[t]{2}{*}{ Number of patients } & \multicolumn{2}{|l|}{ OS } & \multirow[t]{2}{*}{ Statistical details } \\
\hline & & & & Med. (M) & $5 Y(\%)$ & \\
\hline \multirow[t]{7}{*}{ Todd et al. [8] } & $1920-1930$ & $\mathrm{~S} \pm \mathrm{R} \pm \mathrm{HT}$ & 21 & 21 & 7 & \\
\hline & $1930-1940$ & & 40 & $30^{\mathrm{a}}$ & $10^{\mathrm{a}}$ & \\
\hline & $1940-1950$ & & 82 & $35^{\mathrm{a}}$ & $13^{\mathrm{a}}$ & \\
\hline & $1950-1960$ & $\mathrm{CT}$ & 79 & $38^{\mathrm{a}}$ & 15 & \\
\hline & $1960-1970$ & & 168 & $42^{\mathrm{a}}$ & 26 & \\
\hline & $1970-1975$ & & 96 & & $28^{\mathrm{a}}$ & \\
\hline & $1975-1980$ & DOX & 88 & 43 & $25^{\mathrm{a}}$ & \\
\hline \multirow[t]{6}{*}{ Patel et al. [9] } & $1942-1950$ & $\mathrm{~S} \pm \mathrm{R} \pm \mathrm{HT}$ & 14 & $19^{\mathrm{a}}$ & & \\
\hline & $1951-1955$ & CT & 30 & $15^{\mathrm{a}}$ & & \\
\hline & $1956-1960$ & & 53 & $22^{\mathrm{a}}$ & & \\
\hline & $1961-1965$ & & 240 & $21^{\mathrm{a}}$ & & \\
\hline & $1966-1970$ & & 82 & $20^{\mathrm{a}}$ & & \\
\hline & $1971-1975$ & & 54 & $24^{\mathrm{a}}$ & & \\
\hline \multirow[t]{5}{*}{ Giordano et al. [10] } & 1974-1979 & & 93 & 15 & 10 & Multivariate analysis: $P=0.09$ \\
\hline & $1980-1984$ & & 216 & 17 & 14 & \\
\hline & $1985-1989$ & & 235 & 22 & 22 & \\
\hline & 1990-1994 & & 185 & 27 & 29 & \\
\hline & $1995-2000$ & & 106 & 58 & 44 & \\
\hline \multirow[t]{2}{*}{ Andre et al. [11] } & $1987-1993$ & & 343 & 23 & 11 & 1987-1993 versus 1994-2000: $P<0.001$ \\
\hline & 1994-2000 & PAC & 381 & 29 & 28 & \\
\hline \multirow[t]{4}{*}{ Chia et al. [12] } & $1991-1992$ & & & 14.3 & $33^{\mathrm{b}}$ & Total no. of patients 2,150 \\
\hline & $1994-1995$ & PAC, VIN & & 14.8 & $34^{\mathrm{b}}$ & $1991-1995$ versus $1997-1998: P=0.002$ \\
\hline & $1997-1998$ & $\mathrm{AI}$ & & 18.5 & $44^{\mathrm{b}}$ & $1997-1998$ versus $1999-2001: P=0.05$ \\
\hline & 1999-2001 & TRA, CAP & & 21.7 & $45^{\mathrm{b}}$ & \\
\hline
\end{tabular}

$A I$ aromatase inhibitors, $C A P$ capecitabine, $C T$ chemotherapy, DOX doxorubicin, $H T$ hormonal therapy, $M$ months, $M e d$. median, $O S$ overall survival, $P A C$ paclitaxel, $R$ radiotherapy, $S$ surgery, TRA trastuzumab, VIN vinorelbine, $Y$ years

${ }^{a}$ Estimated from the readings of the Kaplan-Meier curves in the article

b Two-year survival rate

advanced breast cancer. Therefore, it is not illogical to assume that disease-free periods after achieving $\mathrm{CR}$ are also being prolonged.

Unfortunately, there is no doubt, at present, that longterm prognosis after treatment of $\mathrm{MBC}$ is, in general, poor. On the other hand, cases that remained disease free for over 20 years after the detection and treatment of $\mathrm{MBC}$ were reported. Factors that affect prognosis in MBC suggested in the literature are the numbers of sites of recurrence, tumor cell burden, patient's age and performance status (PS), post-surgical disease-free interval (DFI), and tumor biology (histological grade, estrogen receptor status, and HER2 status) [3, 14]. The long-term survivors are usually young, with excellent PS, and have limited metastatic lesions [2]. CR is induced more often in MBCs with lower tumor burden, good PS, and predominance of metastases in soft tissues. Patients who have achieved CR demonstrate significantly longer survival compared with those who did not reach $\mathrm{CR}[1,7,15]$. Among those factors, the involvement of a single or a few organs with the metastatic lesions, each of which generally is solitary, characterizes oligometastatic breast cancer (OMBC) $[4,5,14,16]$. The concept of OMBC is a new paradigm proposed by Hellman and Weichselbaum [16], and suggests that patients with oligometastases, either de novo or following systemic treatment, could potentially be cured by ablation of these lesions, whereas more advanced metastatic disease will require more aggressive and effective systemic treatment. The term OMBC has now become synonymous with limited metastases, solitary metastasis, isolated metastases, or minimal metastases. However, OMBC is not yet sufficiently recognized. Some suggest that an aggressive approach with multidisciplinary treatment would be beneficial for potential long-term CR or even cure [1], whereas little evidence is available regarding outcomes of OMBC and their long-term prognosis.

In OMBC, surgical excision for both diagnostic and therapeutic purposes, and/or radiation therapies, is usually 
performed, and consequent disease-free condition is determined as stage IV-NED (no evidence of clinical disease). The largest assessment for the longest period covering 30 years was conducted at the M.D. Anderson Cancer Center [17]. In this study, the authors analyzed results from four phase II trials with isolated recurrence cases (equivalent to $\mathrm{OMBC}$ ) and effects of multidisciplinary treatment were evaluated in the subjects, who underwent curative surgery and/or irradiation for their recurrent lesions to induce stage IV-NED, followed by post-surgical adjuvant systemic therapy similar to a strategy for primary breast cancers. Median observation periods for the survivors till each last follow-up visit were 212.5 months $(N=285)$. Median OS time was 87 months. OS rates were 56,42 , and $26 \%$ for 5 , 10 , and 20 years, respectively, and median relapse-free survival (RFS) time was 42 months with RFS rates at 41, 34, and $26 \%$ for 5,10 , and 20 years, respectively. There were 28 $(10.8 \%)$ cases that remained disease free for over 20 years. Considering the lack of comparative phase III trials testing the effects of chemotherapy versus watchful observation in subjects with stage IV-NED relapsing breast cancer, these results from the M.D. Anderson Cancer Center estimating 20 -year RFS and OS as $26 \%$ would at best imply that clinical cure may have been achieved in those cases who remained in RFS for prolonged periods.

The European School of Oncology-Metastatic Breast Cancer (ESO-MBC) Task Force [5] stated that OMBC, which is characterized by solitary or a few detectable metastatic lesions that are usually limited to a single organ, is a distinct subset of $\mathrm{MBC}$, and that our hope for a cure is most plausible in OMBC with an intensive multidisciplinary approach. Accordingly, the Task Force released guidelines that focus on the present situations and recommend therapeutic approaches for OMBC.

This special feature of Breast Cancer contains four review articles and one original article, addressing various aspects of the possibility of a cure for MBC. The specific topics include molecular-targeted agents aimed at eradicating breast cancer cells, and the roles of cancer stem cells; novel therapeutic agents for improved antitumor effects; advances in understanding of cancer cell biology such as molecular subtyping and possible individualized treatment strategy; perspectives in true cure and/or clinical cure and review of the outcome by local therapies; and the current view of long-term outcome in OMBC from our own experiences and literature review.

We have made significant advances in both diagnosing and treating MBCs. The former is most outstanding in our means of detecting microinvasive lesions early and accurately. The latter advances include various regimens for systemic treatment and methods of radiation therapy, as well as supportive care for undesirable effects of the main therapy. However, those advances have not yet successfully improved the outcome of MBC. Therefore, our expedition never stops and is anticipated to accelerate at the fastest speed ever. Special attention should be drawn to our approach in identifying and optimizing treatment strategy for OMBC, for which we are at a better position to achieve prolonged survival and even possible cure. To fulfill this goal, the evaluation of biomarkers that denote the molecular signature of OMBC is also critical. Our ambition will come true only by the dedicated efforts of each individual, i.e., both physicians and patients, and the insights gained from our experiences with OMBC should eventually be extended to the larger population of patients with MBC.

\section{References}

1. Tan S-H, Wolff AC. Treatment of metastatic breast cancer: chemotherapy. In: Harris JR, Lippman ME, Morrow M, Osborne CK, editors. Diseases of the breast. 4th ed. Philadelphia: Wolters Kluwer/Lippincott Williams \& Wilkins; 2010. p. 877-919.

2. Hortobagyi GN. Can we cure limited metastatic breast cancer? J Clin Oncol. 2001;20:620-3.

3. Hayes DF. General principles of management of metastatic breast cancer. Up To Date 2010; version 18.3.

4. Güth U, Huang DJ, Dirnhofer S, Rochlitz C, Wight E. Distant metastatic breast cancer as an incurable disease: a tenet with a need for revision. Cancer J. 2009;15:81-6.

5. Pagani O, Senkus E, Wood W, Colleoni M, Cufer T, Kyriakides $\mathrm{S}$, et al. International guidelines for management of metastatic breast cancer: can metastatic breast cancer be cured? J Natl Cancer Inst. 2010;102:456-63.

6. Greenberg PA, Hortobagyi GN, Smith TL, Ziegler LD, Frye DK, Buzdar AU. Long-term follow-up of patients with complete remission following combination chemotherapy for metastatic breast cancer. J Clin Oncol. 1996;14:2197-205.

7. Rahman ZU, Frye DK, Smith TL, Asmar L, Theriault RL, Buzdar $\mathrm{AU}$, et al. Results and long term follow-up for 1581 patients with metastatic breast carcinoma treated with standard dose doxorubicin-containing chemotherapy. Cancer. 1999;85:104-11.

8. Todd M, Shoag M, Cadman E. Survival of women with metastatic breast cancer at Yale from 1920 to 1980. J Clin Oncol. $1983 ; 1: 406-8$.

9. Patel JK, Nemoto T, Vezeridis M, Petrelli N, Suh O, Dao TL. Does more intense palliative treatment improve overall survival in metastatic breast cancer patients? Cancer. 1986;57:567-70.

10. Giordano SH, Buzdar AU, Smith TL, Kau SW, Yang Y, Hortobagyi GN. Is breast cancer survival improving? Cancer. 2004;100:44-52.

11. Andre F, Slimane K, Bachelot T, Dunant A, Namer M, Barrelier A, et al. Breast cancer with synchronous metastases: trends in survival during a 14-year period. J Clin Oncol. 2004;22:3302-8.

12. Chia SK, Speers CH, D'yachkova Y, Kang A, Malfair-Taylor S, Barnett J, et al. The impact of new chemotherapeutic and hormone agents on survival in a population-based cohort of women with metastatic breast cancer. Cancer. 2007;110:973-9.

13. Mauri D, Polyzos NP, Salanti G, Pavlidis N, Ioannidis JP. Multiple-treatments meta-analysis of chemotherapy and targeted therapies in advanced breast cancer. J Natl Cancer Inst. 2008;100:1780-91.

14. Burstein HJ, Harris JR, Morrow M. Malignant tumors of the breast. In: DeVita Jr VT, Lawrence TS, Rosenberg SA, editors. 
Cancer. 8th ed. Philadelphia: Wolters Kluwer/Lippincott Williams \& Wilkins; 2008. p. 1606-54.

15. Swenerton KD, Legha SS, Smith T, Hortobagyi GN, Gehan EA, Yap HY, et al. Prognostic factors in metastatic breast cancer treated with combination chemotherapy. Cancer Res. 1979; 39:1552-62.

16. Hellman S, Weichselbaum RR. Oligometastases. J Clin Oncol. 1995;13:8-10.
17. Hanrahan EO, Broglio KR, Buzdar AU, Theriault RL, Valero V, Cristofanilli $\mathrm{M}$, et al. Combined-modality treatment for isolated recurrences of breast carcinoma: update on 30 years of experience at the University of Texas M.D. Anderson Cancer Center and assessment of prognostic factors. Cancer. 2005;104:1158-71. 